\title{
ENKELE KENTEORETIESE BEGRIPPE IN DIE GESKIEDENIS.
}

\author{
Bid Manuel! Jy sit dan stil. Bid, boetie: dis al \\ wat jy kan doen. \\ Hier kóm hy: \\ swart en wit, swart en wit, swart en wit, hier's hy! \\ N. P. van Wyk Louw: Dias).
}

Dit is met groot belangstelling dat ek die artikel van Dr. Floors van Jaarsveld: Geskiedeniswetenskap in Afrikaans (Standpunte, Jrg. 6, nr. 1) asook sy ,metodologies-kritiese' opstel: Oor die ,verstaan' van geskiedenis in sy: Apologetiek en objektiwiteit in ons Kerkgeskiedskrywing gelees het. Hierdie twee opstelle het ek nogal interessant gevind om die volgende twee redes:

1. As kenteoretikus en logikus (vanuit hierdie standpunt wil ek sy werk bespreek) het ek 'n belangstelling in alles wat onder die naam 'metodologie' die boekwêreld insluip en as die benaming ,krities' nog daarby staan, slaan ek dit nooit oor nie.

2. Dit is my eerlike oortuiging (ek is gewillig om dit te verander wanneer die ervaring my anders leer) dat 'n persoon wat oor die grond-

66) G. D. Scholtz: Jaarboek van die Ned. Geref. Kerke 1952, bls. 195. 
slae of teorie of prinsipes van sy vak wil skryf, in die eerste plek oor 'n deeglike kennis van die wetenskapsleer (w.o. formele logika, kennisleer, metodologie en semantiek) moet beskik. Telkens kry ons sulke sg. gewaagde pogings wat gly langs die glibberige rand tussen die filosofie en een of ander besondere vakwetenskap. Gewoonlik beland dergelike pogings dan ook in 'n blote spekulasie wat nóg verdedigbaar nóg aanvegbaar is omdat dit geen empiriese grondslag besit nie en tog ook nie onder die logies-analitiese proposisies geklassifiseer wil wees nie. Die opstel: Oor die ,verstaan' van die geskiedenis toon, wat die konstruktiewe elemente aanbetref, baie duidelik die tekens wat metafisiese spekulasies gewoonlik kenmerk. Om hierdie lg. idolon (om saam met Bacon te praat) uit die weg te ruim, is daar slegs een uitweg en dit is om eenvoudig die elementêre B.A.-kursus in die kennisleer en logika deur te worstel. Laat die geskiedenisstudent in verpligte eenjarige kursus volg in die wysbegeerte - dit sal sy horison verruim en sy kritiese blik verskerp, want waar kom die analitiese funksie van die menslike gees nog so duidelik na vore as juis in die wiskunde, kennisleer en logika? (Om hierdie rede vind ek die jarelange stryd van Prof. A. N. Pelzer vir 'n noodsaaklike kursus in wysbegeerte vir geskiedenis-studente 'n stap in die regte rigting. So 'n kursus word reeds aan die Universiteit van Pretoria gegee, alhoewel die rcgulasie i.v.m. 'n eenjarige kursus in die wysbegeerte moes verval om on roorsienbare omstandighede).

Dr. F. van Jaarsveld pleit in sy twee opstelle hoofsaaklik vir die volgende: Kennis van die teorie of grondslae van die geskiedenis deur behoorlike leiding van die betrokke dosent in die vakwetenskap, geskiedenis. Met die pleidooi stem ek heelhartig met hom saam. (Die metode wat aangevoer word, nl. kennismaking met die jongste literatuur word egter nie deur hom toegepas nie, want in hoofsaak is al die wysgerige opvattings waarop hy terug val, gegrond op die werk van Dilthey wat al oor die 40 jaar oud is.)

Daar is veral 4 begrippe in die opstelle wat nooit wetenskaplik buite die sfeer van die kennisteorie en logika ontleed kan word nie, maar wat tog deur Dr. V. J. gebruik word alhoewel hy uitdruklik beweer: Ook nie, kennisteorie' kom hier ter sprake nie. (Oor die ,verstaan van die geskiedenis, p. 54). Wat Dr. Van Jaarsveld onder ,kennisteorie' verstaan, weet ek nie, maar in die sistematiese wysbegeerte het die begrip 'n besondere betekenis sodat 'n hele aantal proposisies in sy opstel beslis van kenteoretiese aard is. 'n Mens kan nie .,ins Blaue hinein", los van die lang geskiedenis van die sistematiese wysbegeerte praat nie. Egte wetenskaplikheid reken altyd met die resultate van die verlede. 
Die vier begrippe wat ek hier wil noem, is :

a. Die begrip kausaliteit,

b. Die begrip subjek-objek,

c. Die begrip belewenis (Duits eintlik Erleben. Dilthey gebruik baie meer die begrip Erleben as Erlebnis. Dr. Van Jaarsveld se verwysing op p. 55 na p. 191 in Dilthey VII is dus foutief. Dilthey praat hier van Erleben. Ausdruck und Verstehen en nié van Erlebnis ... nie. Daar is ' $n$ besliste verskil tussen hierdie twee begrippe.)

d. Die begrip metode.

\section{a. Die begrip kausaliteit.}

Oor die begrip is al boekdele volgeskryf, veral deur metafisici wat die kausaliteit beskou as 'n soort garing wat alle dinge aan mekaar vashou. Dit word dan beskou as 'n reële entiteit wat nou wel nie so hard soos 'n tafelblad is nie, en wat versigtigheidshalwe as iets geesteliks of psigies beskou word. (Hoe vaer 'n begrip gewoonlik, hoe meer gees is daar. Miskien verklaar dit die vaagheid in die geesteswetenskappe).

Wanneer iemand nou bewerings maak oor die gebruik van die begrip binne 'n bepaalde vakwetenskap, lyk dit vir my nog altyd op die enigste wetenskaplike weg om die begrip binne daardie sisteem van vakwetenskaplike proposisies op te spoor (of dit nou versweë is of nie) en die gebruik van die besondere begrip na aanleiding van daardie aantal proposisies te konstrueer. Wat gewoonlik gebeur, is heeltemaal iets anders. Die vakwetenskaplike (wat dikwels nogal 'n skrale kennis het van die wysgerige gebruik van die begrip) skryf vir die leek ' $n$ aantal werke oor: New pathways in science, The modern scientific outlook, How I see the psysical reality, ens., en siedaar, hier is die bronnemateriaal, die dokument, vir hom/haar wat oor die kausaliteit wil skryf.

Hier lê my groot kritiek op Dr. Van Jaarsveld en Dr. Ria Hugo wat onkrities 'n aantal bronne aanvaar as die waarheid. By albei steek die historikus die duidelikste sy kop uit, want dit is inderdaad baie eenvoudiger om aan te haal as om krities die waarheid van die aanhaling langs die weg van die analise te bepaal. Hoeveel moeite is gedoen om by die gebruik van die begrip kausaliteit die verband met die waarskynlikheidsrekening te bepaal? Sal die werk van die logiese positiwiste waaronder die werk van Carnap bv. ooit gelees word? Hier stel ons weer vas: Voorafgaande wetenskaplike arbeid word gewoonweg negeer, en deur 'n beroep op populère bronne, word ander platgeslaan.

Dilthey se opvattings oor natuurwetenskaplike kausaliteit is beslis verouderd en gebonde aan die fisikaliese teorieë van ongeveer 1850 . 
Op hierdie punt wil ek radikaal verskil van Dr. Van Jaarsveld wat die sg. natuurwetenskaplike kausaliteit verwerp en praat van 'n eie reëlmaat en ritme in die geskiedenis. Wat is nou eintlik die verskil? Kritiseer hy die aanvaarding van die kausaliteitsprinsipe of die deterministiese opvatting as voorspellingsmetode in die fisika omdat dit nie op die historiese feite en verloop van toepassing is nie? Is die deterministiese standpunt prinsipieel uitgesluit as metode in die geskiedenis? Is dieselfde kennisteoretiese besware teen 'n deterministiese kenbegrip in die fisika van toepassing in die geskiedenis as vakwetenskap? Dit is absoluut noodsaaklik om eers rekenskap te gee van die antwoorde op dergelike vrae voordat ons kan besluit pro of contra kausaliteit in die geskiedenis as werklikheid. Laat my toe om nog twee vrae te stel: Is die warm word van my hand wanneer ek dit voor die kaggel hou, nie ook 'n historiese gebeurtenis nie? Is die langsame herwin van die bewussyn nadat ek 'n verdowingsmiddel ontvang het ook nie 'n gebeurtenis wat histories verloop nie?

Dr. Van Jaarsveld kom met 'n verkeerde interpretasie voor die dag wanneer hy verwys na die aanhaling uit Dilthey: „die Geschichte weiss nur von den Verhältnissen des Wirkens und Leidens, der Aktion und Reaktion." (VII, p. 197). Hy beweer : ,die geskiedenis ken slegs lyding, geduld, aksie en reaksie, jubel en jammer." Hiermee word die objek van die geskiedenis die psigologiese aandoeninge van die enkeling. Dit is tog duidelik dat Dilthey hier dink aan Leiden in die sin van die Aristoteliese kategorie: paschein. Verder: Is "Aktion" en „Reaktion" nie juis kousaal verwant nie?

In die geskiedenis is die dokument die gegewe materiaal en dit gaan daar in die eerste instansie om die interpretasie van die gegewe materiaal en nie om die vasstelling van die waarheidgehalte daarvan nie. Dilthey het bv. sekere uitsprake gemaak en in die geskiedenis van die wysbegeerte is dit ook van die grootste belang, maar die kritiese metodoloog moet nie alleen die historisiteit daarvan in ag neem nie, maar juis die waarheid daarvan bepaal. Al het Dilthey honderdmaal beweer: daar bestaan net agt planete, is dié proposisie nog gladnie waar nie. Histories is die bewering wel van belang, maar ons agting vir Dilthey moet ons geensins ons oë laat sluit vir die waarheid nie. Daarom vind ek dit jammer dat kausaliteit, natuurwetenskaplike kausaliteit ens. na 'n onvolledige ontleding eenvoudig verwerp word omdat daar apriories uitgegaan word van die andersheid, uniekheid ens. van die geesteswetenskappe. Om hierdie rede vind ek dit noodsaaklik dat die wetenskapsleer in sy geheel behoorlik bestudeer word alvorens 'n geskiedkundige rekenskap gee van die grondslae van sy wetenskap in terme van begrippe met 'n wye kenteoretiese en logiese gebruiksveld. 
b. Die begrippe subjek en objek.

Op bladsy 63 (Oor die ,verstaan' van die geskiedenis) beweer Dr. Van Jaarsveld: „Die onderskeiding van subjek - objek val hier as 't ware weg. ..." Wanneer daar van kennisteorie nie sprake is in 'n opstel nie, moet ons ook probeer om alle kennisteoretiese begrippe te vermy. Hier het ons egter die basiese begrippe waarop 'n kennisleer moet berus en hulle word gebruik in 'n kennisteoretiese verband. Ek wil nie hier volledig op die saak ingaan nie maar verwys die leser na die mooi fenomenologiese ontleding van die kenverskynsel deur Nicolai Hartmann (Grundzüge einer Metaphysik der Erkenntnis, Leipzig, 1921). Ek kan eenvoudig nie sien hoedat die subjek-objek skema by 'n ken - of verstaan-relasie ooit kan verval nie, want $E k$ (subjek) ken tog altyd Iets (objek) of verstaan tog lets (objek). Hier is tog nooit sprake van metafisiese entiteite nie, bv. die $E k$ as 'n ding van vleis met 'n paar nr. 7 skoene aan, maar juis van kenteoretiese begrippe. Reeds Brentano het daarop gewys dat die psigiese verskynsele almal een kenmerk het en dit is hulle gerigtheid op iets. Dilthey noem dit: Intentionalität. 'n Sin soos die volgende: "Soos Dilthey sê, lewe ,vat' hier lewe" is vir my so dubbelsinnig dat 'n mens die betekenis daarvan nie met 'n soplepel kan opskep nie, want die vier woordjies word nie alleen in 'n ongewone sin gebruik nie (vergelyk maar die metaforiese .vat'), maar die betekenis van die eerste lewe is nié dieselfde as die van die tweede nie. Ons moet dit eerlik erken dat Dilthey soms baie digterlik was en digterlike waarhede is altyd waar omdat dit enigiets kan beteken - of niks.

\section{c. Die begrip belewenis.}

Ek weet nie presies waarom die skrywer hier nie van belewings gepraat het nie, want ek glo dat ons dié woord in die Afrikaanse spreektaal meer gebruik as belewenis. Dit is moontlik dat Dr. Van Jaarsveld wou onderskei tussen die belewing (ervaar) van die belewenis en die belewenis self. Belewenis moet dan ' $n$ inhoud van die ervaring op ' $n$ bepaalde tydstip in die historiese realiteit wees. Daar is iets te sê vir die onderskeiding, maar ek het dit hier teen iets anders. Dr. Van Jaarsveld wil probeer om subjektiwiteit sover moontlik te vermy en dit deur 'n metode te ontwerp wat gegrond is op die begrippe: Belewenis, Uitdrukking en Verstaan. Ek is oortuig daarvan dat enige dergelike poging wat ansluit by die beslis positiwistiese beskouings van Dilthey, alleen kan strand in die psigologisme wat niks anders is nie as ' $n$ metafisiese regverdiging van die subjektiwisme. Die belewenis word uitgedruk in tekens, dus geobjektiveer. Hierdie geobjektiveerde tekens word nou bestudeer (ge-interpreteer) om sodoende agter die 
sin of betekenis (die oorspronklike balewing) te kom. By die interpre tasie speel die inlewing en verstaan 'n belangrike rol. Ons kan dit so voorstel: 'n Subjek a het ' $n$, belewenis' b op 'n bepaalde tydstip $t$ en dit word geobjektiveer in die teken $d$. Historikus $h$ rig sy aandag op $d$ en interpreteer dit as b op die moment $t$. Hier wil ek nou twee vrae stel:

1. Hoe kom die probleem van die tydsverloop, dus van die historisiteit of aaneenskakeling, hier ter sprake indien ons bv. meer as een $a, b, d$ en $t$ het?

2. Hoe vermy ons die psigologisme? Waar lê die verskil tussen die psigologiese verloop van die proses en die historiese verloop wanneer ons ons op Dr. Van Jaarsveld se standpuit stel?

'n Persoon soos Hodges (wat 'n mooi boek in Engels oor W. Dilthey geskryf het) het ook die waarskuwing uitgespreek dat die wysger:ge oortuigings van Dilthey baie maklik tot 'n psigologisme kan lei. Dit is grotendeels te wyte aan Dilthey se poging om 'n geesteswetenskaplike psigologie te ontwikkel wat as basis moet dien vir al die geesteswetenskappe. (Daarom het ek hom hierbo bestempel as 'n positiwis of psigologis).

Dr. Van Jaarsveld moes hom meer konsekwent bepaal het by sy onderskeiding tussen geskiedenis-as-werklikheid en geskiedenis-aswetenskap. Wanneer ons soek na die prinsipes of grondslae van die geskiedenis, bedoel ons tog immers die geskiedenis as 'n wetenskap. Wanneer ek nou van die belewing van 'n subjek en die objektivering daarvan praat, is ek besig met die ontstaan van die inhoud van die dokument. Hierdie moment hoort dus tuis by die geskiedenis-werklikheid, want die belewing word gesien as basis of grondslag (as die ontologiese samestelling) van die besondere objek waarmez die histori kus werk. Die benaming ,belewenis' asook die interpretasie van die benaming help ons niks verder nie. Ons kannie van $X$ iets sê en dit dan sommer goedsmoeds op $\mathrm{Y}$ gaan toepas nie. Wat vir die geskiedenis as wetenskap van waarde is, is die belewing as moment in die bewussyn van die historikus, want na aanleiding hiervan vorm hy vir hom 'n samehang of voorstelling van die verloop.

Dr. Van Jaarsveld moes liewer by Dilthey se omskrywing van die gegewene van die geesteswetenskappe as die "geobjektiveerde lewe" aangesluit het (die Geisteswissenschaften haben als ihre umfassende Gegebenheit die Objektivation des Lebens, VII, p. 148) as om die onheldere begrip Erlebnis te gebruik.

Wanneer ons die moeite doen om die begrippe Erleben of Erlebnis by Dilthey te analiseer, vind ons dat dit vir hom eintlik innerlike toe- 
stande, prosesse of aktiwiteite is in sover dit bewus deurleef of ervaar word, maar op daardie moment nie objekte van die introspeksie gemaak word nie. Die aandag of bewussyn word gekonsentreer op die objektiewe inhoud waarteenoor ons 'n bepaalde houding inneem en nie op die houding self nie.

Ek vind dit daarom besonder jammer dat Dr. Van Jaarsveld hierdie besondere begrip nl. ,houding' (Verhaltung) heeltemaal oor die hoof gesien het. Dit bring mee dat sy aanknoping by Dilthey glad geen aanknoping is nie, maar 'n blote gebruik van 'n paar woorde wat ons by Dilthey aantref. Onder houding (Verhaltung) verstaan Dilthey die betrekking (verhouding) tussen die bewuste subjek en die inhoud of objek waarvan hy bewus is. So onderskei hy dan tussen ken, voel en wil. Die werklike eenhede van die geestelike lewe is nie bepaalde gewaarwordinge of gevoelens nie, maar die gehele teaksie van die hele subjek tot die situasie waarmee hy gekonfronteer word. Elke sodanige reaksie is opgebou uit ken-, voel- en wils-elemente. Dit is noodsaaklik om hierdie aspek te beklemtoon, want dit verander die saak heeltemaal en alleen deur klem hierop te lê, kan ons enigsins die geskiedenis-as-werklikheid sien, nie bloot as 'n psigologiese proses nie, maar as die reaksies van mense op bepaalde gebeurtenisse. Belewings is vir Dilthey nie lewensgebeure, lotgevalle ens. soos by Dr. Van Jaarsveld nie, maar juis die reaksie op dergelike lewensgebeure, lotgevalle, ens.

\section{d. Die begrip metode.}

'n Wetenskaplike wat soek na metodologiese grondslae en prinsipes sonder om eers rekenskap te gee van wat metodologie (metodeleer) is, kan geen deeglike wetenskaplike, metodologies-kritiese opstel skryf nie. Dit verbaas my dat so baie wetenskaplikes kan praat van 'n historiese metode, natuurwetenskaplike metode, wiskundige metode sonder om eers duidelikheid te hê oor wat 'n metode in die algemeen en wat metode in die wetenskappe beteken. Hoe onderskei ons bv. tussen tegniek en metode? Wat is die sin of bestaansregverdiging van 'n metode? Gewoonlik aanvaar ons dat 'n metode 'n weg is waardeur ons vanaf 'n bepaalde vertrekpunt tot by 'n gestelde doel kan kom. Hierdie weg kenmerk homself as:

a. nie bloot willekeurig nie, maar bepaald deur die einddoel wat gestel is, sowel as die objek wat ondersoek moet word.

b. nie logies onsamehangend nie, maar gebaseer op basiese prinsipes waarvoor in baie gevalle geen verdere regverdiging gevind kan word nie. (Is dit pragmaties bepaald?) 
Daar is vir my 'n reeks moeilike probleme wat nie somaar oor die hoof gesien kan word nie. Die vernaamste vertrekpunt is nie 'n gegewe feit of waarheid nie maar 'n vraag. Ek wil dit hier dogmaties stel dat geen struktuur wat aanspraak maak op die benaming wetenskaplike navorsing metodies geregverdig is indien dit nie voorafgegaan word deur ' $n$ duidelike vraagformulering nie. (Dit is jammer dat ons nog oor geen logiese struktuur-analise van die vraag beskik nie - of soiets wel moontlik is, laat ek vir die oomblik daar. Ek vind dit tog noodsaaklik. Miskien sal een van die simboliese logici nog so iets aandurf!)

Waar Dr. Van Jaarsveld dus praat van boeke wat 'n metodiese grondslag van die apologetiese element gebring het, stem ek hoegenaamd nie met sy beskouing van die begrip metode saam nie. As iemand 'n proposisie wil bewys (dit mag resultaat van sy studie wees of vooropgestelde doel) gaan hy volgens 'n metode te werk wat as metode nie te onderskei is van 'n bewys dat die proposisie $p$ juis vals is nie. Metodies kan ons dus nie 'n grondslag lê waarop die apologetiese element gefundeer kan word nie.

Waar daar deur Dr. Van Jaarsveld gehamer word op geheles en waar hy Prof. A. N. Pelzer skerp aanval omdat hy die Z.A.R. ,soos 'n eiland in die Suid-Afrikaanse wêreld gaan beskryf", wil ek tog net waarsku dat die begrip geheel 'n baie relatiewe en soms baie willekeurige begrip is en dat hierdie argument, wat teen Prof. Pelzer gebruik word, sy wetenskaplike waarde daarmee inboet. Ons weet almal dat die Gestalt-psigoloë wys op geheles en dat ons sekere dinge teenoor 'n agtergrond moet sien en in verband met ander dinge waarmee dit verband hou. Solank hierdie argument gebruik word sonder die afdoende bepaling van wat 'n geheel is en wat die bepaalde geheel is. vrees ek sal hierdie argument alleen hulle oortuig wat graag oortuig wil wees. 'n Saaklike argument word dan 'n argumentum ad hominem.

Terwyl ons besig is met hierdie saak wil ek 'n ander redeneerwyse van Dr. Van Jaarsveld onder oënskou neem. 'n Bepaalde bewering word gemaak wat somaar gelyktydig met die sogenaamde waarheid daarvan as 'n sweep moet dien om een of ander historikus (gewoonlik uit die ,Noorde') 'n hou mee toe te dien. Dan word 'n getalletjie aan die einde van die, waarheid' geplaas en onder aan die bladsy verskyn jou werklikwaar die naam van die grote $X$ (wat tog onmoontlik verkeerd kan wees) en die betrokke boek waarin hy sy waarhede opgeteken het. Nou het ek geen beswaar as die waarheid van dergelike proposisies ten minste voorlopig onder 'n vraagteken geplaas word nie, maar wat gebeur? 'n Naam van 'n filosoof (en by dit alles 'n metafisikus) word gewoonlik gebruik om die waarheid waarder te 
maak. 'n Pragtige argumentum ad verecundiam. (Ek noem geen name nie want dit is baie maklik om in so 'n bewering ' $n$ apologetiese tendens te sien!)

Dr. Van Jaarsveld verwyt sommige historici hulle skerpe en radikale onderskeiding tussen swart en wit maar hy huldig in sy kritiek tog dieselfde swart en wit standpunt. Nêrens kry ons 'n enkele sin waarin hy nog iets goed in sy teenstander se konstruktiewe werk sien nie. Alles is swart wat behoort tot die Noordelike skool, die res is wit. Die gronde vir 'n onderskeiding tussen 'n Noordelike en Suidelike skool kan ek nie raaksien nie. Buitendien is hierdie onderskeiding onkrities uit die letterkundige wêreld oorgeneem en selfs hier berus dit op geen ander gronde as die polemiese óf, soos Dr. Van Jaarsveld dit noem, die apologetiese nie. Wat so 'n onderskeiding ooit vir die geesteswetenskappe kan beteken, slaan my eenvoudig dronk. 'n Klassifikasie moet minstens aan sekere vereistes voldoen $\mathrm{nl}$. aan die eise van volledigheid, duidelike omlyning en identiteit van prinsipe.

Ten slotte nog 'n paar opmerkings oor die filosofies-metafisiese standpunt van Dr. Van Jaarsveld t.o.v. die geskiedenis. Hierdie metafisiese standpunt wortel soos hy wil laat voorkom in die Vastelandse geesteswetenskaplike rigting: Dilthey, Litt, Rothacker, Ehrlich, Stein, Misch en Bollnow en hierby nog 'n paar ander: Nietzsche, Croce, Ortega Y Gasset en Heidegger. In breë trekke stem hierdie genoemde geleerdes se opvattings ooreen. Dr. Van Jaarsveld se bibliografie toon egter aan dat hy die kritiek op hierdie filosofiese standpunte nie ken nie of nie wil ken nie. Ek dink maar aan twee werke wat tog in Europa goed bekend is: H. Gomperz se 'Interpretation' en Julius Kraft se 'Die Unmöglichkeit der Geisteswissenschaft' (1934). Wanneer Dr. Van Jaarsveld alleen die foutiewe interpretasies van historiese feite deur die Suid-Afrikaanse historici sou naspoor en aantoon, sou ek sy deeglikheid en noukeurigheid bewonder, maar wanneer hy 'n onverdraagsame houding t.o.v. 'n filosofiese standpunt inneem, voel ek dit my plig om te wys op die relatiwiteit van alle matafisiese standpunte.

Wat betref die filosofieë oor die geskiedenis-as-werklikheid (wat gewoonlik onder die naam van ,filosofie van die geskiedenis' gaan) is dit my eerlike mening dat wetenskaplikes eers langs eerlike verstaanbare wyse hulle bydraes op die gebied sal moet lewer alvorens ons 'n skielike verandering aan al ons universiteite kan verwag. Trouens die uitdrukking ,filosofie van die ...' laat mens altyd dink aan Hegel se spottery met die gebruik van die woord in Engeland waar Newton 
die roem gehad het van 'n groot filosoof en waar ,,diejenigen Instrumente, die nicht unter eine besondere Rubrik magnetischen, elektrischen Apparats gebracht werden, die Thermometer, Barometer usf. philosophische Instrumente" genoem word. Hegel wys ook op 'n werk: The Art of preserving the Hair, on Philosophical Principles, neatly printed in post 8 ., price 7s. Ons opvattings oor die geskiedenis-aswerklikheid sal altyd gekleurd wees deur ons kommunisme, sosialisme, materialisme, calvinisme, ens. Hieroor kan geen verstandige rusie gemaak word nie.

En tog: die redelikheid moes ons behou.

(N. P. van Wyk-Louw: Dias).

Universiteit van Pretoria.

A. M. T. Meyer. 